\title{
Unfinished Business?
}

\section{Faith Communities and Reconciliation}

\section{in a Post-TRC Context}
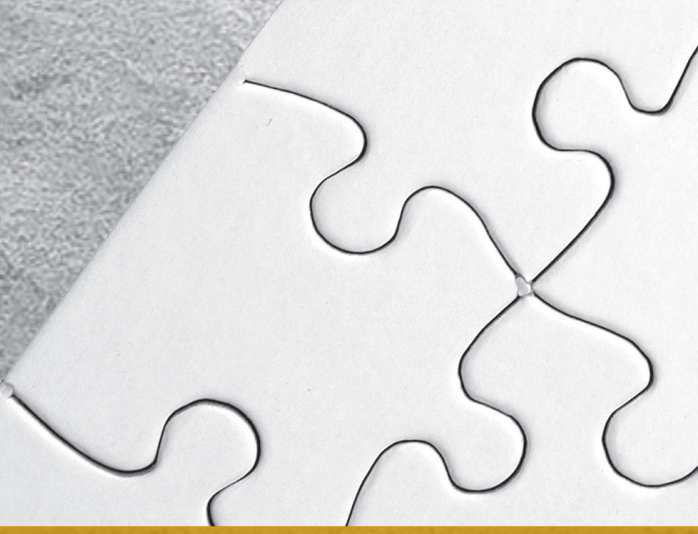


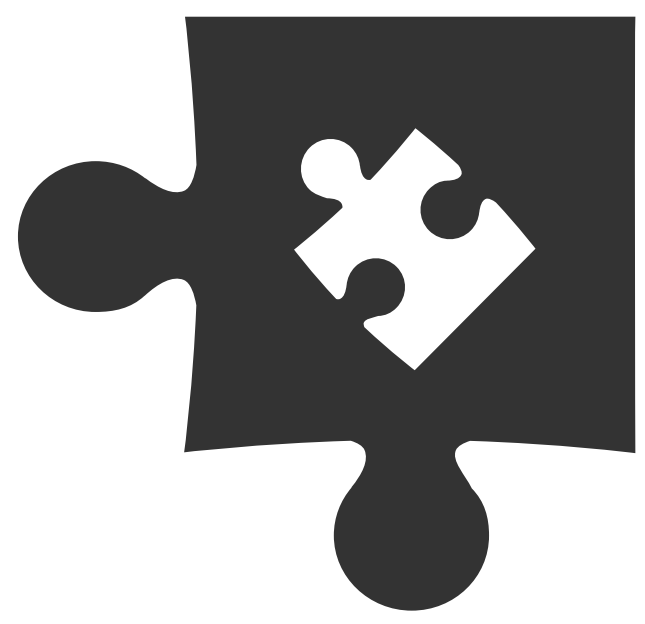

\section{Editors' notes}

When picking up this publication, it will be quite understandable that a few questions may arise in the reader. "Why yet another book on the TRC?", may be one. Why only now a publication on an event that took place five years ago? Have the authors and editors not perhaps missed the proverbial bus with this one? It is, therefore, necessary to explain exactly why this publication and why now, why only in 2019. Chapter three of this publication, chronicles the reenactment consultation of the TRC Faith Communities' Hearing in 2014. At the end of the consultation, Dr Frank Chikane chaired a session on "The way forward". During this session Chikane acknowledged that, despite the many successes and progress made in the years following the TRC hearings, there was a distinct feeling among delegates that "[a]s leaders and members of the communities of faith we are conscious of unfinished business in the process of transformation in our nation." A suggestion from the floor called for the establishment of a "Truth and Reconciliation Continuation Group". It was clear during and immediately after the consultation there was renewed excitement and new found energy for working towards reconciliation and justice. It was hoped that efforts toward reconciliation and justice will once again take a prominent place, not only on the 


\section{| Editors' notes |}

main agenda of the South African Council of Churches, but also on those of the faith communities that were represented at the consultation. Today, five years after the consultation, we realise that the process of reconciliation based on the original recommendations of the TRC and the recommendations made by the consultation will for long remain challenges our society and to a large extent remain in a vulnerable position of being "unfinished business" - hence, also, the name of this publication. It is our hope that revisiting the re-enactment and via this also the original TRC Faith Communities' Hearings readers of this publication will ponder the state of reconciliation in our communities today, what this may require of them individually and as faith communities and that it may once again inspire and renew energy and commitment to pursue reconciliation in South Africa.

The publication consists of two parts that follow on a foreword written especially for this publication by Emeritus Archbishop Desmond Tutu and Reverend Mpho Tutu van Furth, who both played a key role in the re-enactment consulation five years ago. In the first section of the publication two well-known South Africans share some of their memories of the run-up to and the Faith Communities' Hearings of the TRC. Piet Meiring, a well-known Dutch Reformed theologian at the time was nominated to serve by TRC commissioner, Desmond Tutu, himself. Brigalia Bam served as General Secretary of the South African Council of Churches, that was instrumental in the establishment and determination of the composition of the TRC. These two contributions - on the preparations for hearings by Bam and the hearings themselves by Meiring - tell more about the behind-the-scenes events and emotions, the deliberations and considerations, the hopes and expectations of, not only the TRC commissioners and chairpersons, but also of President Mandela himself for the extraordinary reconciliatory responsibility placed on the Commission.

The second part of the publication begins with a summary of the two-day reenactment of the TRC Faith Communities' Hearings. To give a full account of the depth and breadth of the seventeen submissions made by faith communities at the occasion will be impossible and outside of the ambit of this publication, so we highlight the central achievements, but also the unfortunate failures of faith communities that did not live up to the promises made before the TRC two decades ago. In the process, many new challenges emerged in our communities since that time and that should be put on all faith communities' agendas. These are identified and it is shown in most submissions how, today still, addressing the old and the new challenges are intricately connected with a lack of justice and reconciliation in our country. 
The above-mentioned chronicle is followed by a collection of six essays that reflect on the TRC, the re-enactment thereof and/or the past, present and future challenges we face as a nation. A number of local and international scholars from diverse denominational and religious backgrounds (Jaap Durand, Vincentia Kgabe, Eddy van den Borght, Nico Koopman, Marichen van der Westhuizen, Rashied Omar and Martin Leiner) were asked to reflect, from their own contexts, on what they had heard and what they made of the submissions during the re-enactment consultation. Most were present at the consultation and shared their experiences with the meeting on the last day of the consultation. Others did so only later and are included in this publication.

With this in mind, we would like to thank all those who shared their memories and perspectives with us - be it in the form of essays or submissions during the TRC re-enactment consultation. Thank you for entrusting us with these. We would like to thank the Beyers Naudè Centre for Public Theology and the Desmond and Leah Tutu Legacy Foundation for initiating and hosting the re-enactment and for supporting this publication after all these years. We are also grateful to the Faculty of Theology at Stellenbosch University for its Hope Project that financed the consultation, as well as this publication. We also wish to thank our publisher, African Sun Media for the professional way in which they made the publication of this book a reality.

As editors we are extremely grateful for the privilege to have worked on this publication. Although five years down the line from the re-enactment event, we believe it remains relevant, even necessary, to revisit that memorable event, especially in a time when increased racial tensions and polarisation in our society seems all but a fact of life. May this publication contribute to rekindle the dream of and the commitment of all South African people of faith towards justice, peace and reconciliation. 